\title{
ÂNGELO MONTEIRO E AS RAÍZES: ENTRE O CLÁSSICO E O AGORA
}

\section{ÂNGELO MONTEIRO AND THE ROOTS:}

\section{BETWEEN THE CLASSICS AND NOW}

\author{
Adrian Lincoln Clarindo*
}

Resumo: O trabalho apresenta uma visão sobre algumas ideias que suscitam certa caracterização da "época teórica" alcunhada como "pós-modernidade". As ideias mostrariam o prefixo "pós" carregado de uma desamarra entre o pensamento contemporâneo e aquele que se tem como clássico. Por meio do poema "Os sem raízes”, que retrata o indivíduo ao extremo dessa desamarração, do poeta alagoano Ângelo Monteiro, o trabalho aqui propõe uma problemática: seria o indivíduo dos dias atuais tão fragmentado (como o pintam pensadores do atual como Hall e Bauman) que se tornaria órfão totalmente do sistema de signos e referenciação? É este o ponto que investigaremos.

Palavras-chave: Pós-modernidade. Raízes. Ângelo Monteiro.

\begin{abstract}
This paper presents a view on some ideas that raise certain characterization of a "theoretical time" named as "postmodernity". These ideas show the prefix "post" loaded with unties between contemporary thought and the one we have as "classic". Through the poem "Os sem raízes" which portrays the person to the extreme of this unbindness, by the poet alagoano Angelo Monteiro, our work here proposes a problem: would the person of today so fragmented (like current thinkers, Hall and Bauman, would suggest) that he/she would become an orphan of the system of signs and referencing? This is the point that we intend to investigate.
\end{abstract}

Keywords: Postmodernity. Roots. Ângelo Monteiro.

$\overline{~ M e s t r e ~ e m ~ L i n g u a g e m, ~ I d e n t i d a d e ~ e ~ S u b j e t i v i d a d e ~-~ U E P G . ~ E-m a i l: ~ a d r i a n l i n k @ g m a i l . c o m ~}$ 
Desfolho-me a cada dia/

Sem que a copa se desprenda do tronco/

Nem o tronco da raiz.

E a copa verde ou amarela,/Falará por mim.

(Ângelo Monteiro)

Aos que acompanham o rumo dos estudos filosóficos, literários e teóricos, duma maneira geral, que mais abrangentemente tocam as universidades públicas do Brasil, torna-se relativamente claro quais são os focos abordados pelas discussões levantadas dentro das academias contemporaneamente. O sujeito, a subjetividade e a linguagem nos tempos atuais sofrem e também causam o deslocamento de grandes verdades numa visão objetiva para "menores" subjetivas. $\mathrm{O}$ linguista francês Ferdinand de Saussure, no começo do século vinte, com seus ditos, depois escritos por seus discípulos, sobre a metapesquisa que a linguagem verbal necessitaria, é tido, por vezes, como o ponto de partida para uma grande avalanche de revoluções, desconstruções e reviravoltas no pensamento humano sobre si mesmo. Com fenômeno semelhante acontecendo no mundo científico da física, para os que estão cientes da teoria dos quanta, da relatividade do tempo, da teoria do big bang, sem citar os onze universos das supercordas, o que pode se perceber nesta leva contemporânea de estudos é uma grande análise das coisas por elas mesmas.

Numa onda de emaranhamento, com o planeta conectado pelas tecnologias de comunicação, a facilidade de acesso a informações, e as verdades, portanto, limites, balançados, a divisão imaginária das disciplinas também enfraqueceu. Assim, surge a possibilidade de se analisarem fatos num entrelaçar das teorias. $\mathrm{O}$ " $2+2$ $=4$ ", antes analisado apenas pelo campo da Matemática, agora pode ser objeto das Letras, da Biologia etc. É como se a Pangeia das teorias voltasse a se construir. Jonathan Culler, o pensador americano, à luz de uma gama teórica principiada na França desde Saussure quanto ao metaolhar para a linguagem por ela mesma, daí seguindo com filósofos como Derrida, que tencionavam desconstruir pilares ideológicos ocidentais, percebe que os rumos que os estudos tomavam, então, montavam um novo corpo de análise, em que se encontram e não se distinguem tanto Literatura da Filosofia, ou mesmo a Sociologia da História, por exemplo. A essa nova perspectiva de pesquisa, Culler chamou apenas de "teoria", e esta não seria, como se poderia pensar, a boa nova solucionadora de tudo:

A teoria faz você desejar o domínio: você espera que a leitura teórica lhe dê os conceitos para organizar e entender os fenômenos que o preocupam. Mas a teoria torna o domínio impossível, não apenas porque há sempre mais para saber, mas, mais especificamente e mais dolorosamente, porque a teoria é ela própria o questionamento dos resultados presumidos e dos pressupostos sobre os quais eles se baseiam. A natureza da teoria é desfazer, através de uma contestação de premissas e postulados, aquilo que você pensou que sabia, de modo que os efeitos da teoria não são previsíveis. (CULLER, 1999, p.24). 
A natureza da teoria de Culler é desconstrutora. Paradoxalmente, esta teoria realmente desconstrói tudo o que quer quando como uma aranha agarra o objeto dentro de sua teia e se vê ali sem obstáculos para desmembrá-lo e demonstrá-lo quanto a seus desencaixes e aporias. Ela, porém, não segue um dos mandamentos de sua origem que é a meta análise, aquela cuja linguagem de Saussure deveria fazer. A desconstrução tenta desconstruir tudo, menos a si mesma. Logo, o que temos é, embora pensadores como Terry Eagleton muito precisamente já tenham postulado que há um "depois da teoria", uma influência ainda forte nas pesquisas acadêmicas quanto à desestabilização de fundamentos. A identidade do ser é colocada em questão muito fortemente pelo fato, dizem alguns pensadores, da fluidez rápida dos momentos da vida, da interconectividade, da rapidez da tecnologia, da possibilidade de fácil deslocamento. Logo "parece que todos estamos estudando identidades hoje em dia", disse Pennycook (2006, p. 80).

Dentro desse quadro teórico, o pesquisador Stuart Hall explica esta busca de se entender o que é identidade por meio de uma análise do desenvolvimento histórico do mundo contemporâneo. Hall ressalta, num primeiro momento, a identidade do sujeito do Iluminismo: centrado em si, racional, individualista e frequentemente "descrito como masculino" (2003, p.11). Em seguida, Hall situa alguns fatores que acabam por descentralizá-lo. Um exemplo é a questão psicológica apontada por Freud e outros psicanalistas sobre o inconsciente. A teoria freudiana é de que nossa identidade, assim como nossa sexualidade, é formada com base em processos psíquicos e simbólicos do inconsciente; este que, por sua vez, funciona de acordo com uma lógica muito diferente da Razão tida como fundamental para os iluministas. Tal ideia "arrasa o conceito do sujeito cognoscente e racional provido de uma identidade fixa e unificada - o 'penso, logo existo', do sujeito de Descartes" (2003, p. 35). Em seguida, Hall pontua o sujeito sociológico que releva questões sobre a relação de si com a sociedade. A noção de sujeito sociológico vai refletir, para Hall, a crescente complexidade do mundo moderno e o entendimento de que um núcleo interior do sujeito não era autônomo e autossuficiente, mas "era formado na relação com 'outras pessoas importantes para ele', que mediavam para o sujeito os valores, sentidos e símbolos - a cultura - dos mundos que ele/ela habitava" (2003, p. 14). E em um terceiro momento, que é o atual, temos o sujeito pós-moderno. Neste, a identidade se daria pelas várias posições que ele ocupa na vida social, os vários “eus”, por vezes contraditórios, que desempenha na sociedade. Seria aquele que vive não só em um mundo fragmentado, mas cuja própria identidade, o próprio sujeito, porque é o sujeito do inconsciente freudiano, reconhece-se também fragmentado e que é construído por meio da linguagem, desde que Saussure, Hall explicaria, afirma que nós não podemos nos dizer "autores" do que dizemos já que a linguagem precede nossa existência (2003, p. 40). Por isso, a identidade do sujeito 
pós-moderno se torna instável, ou seja, "a identidade completa e coerente" - escreve Hall - "é uma fantasia" (2003, p. 13).

Assim, o autor nos mostra a fragmentação do homem atual, ideia não fugidia dos pensamentos do pensador polaco Zygmunt Bauman. Em seus livros, Bauman, enfatizando a vida rápida ao redor do uso de aparelhos interconectados e fatores como a globalização, internacionalização, além do movimento desenfreado do ser humano sobre a terra, tece a contemporaneidade como "líquida". O autor pontua: "no admirável mundo novo das oportunidades fugazes e das seguranças frágeis, as identidades, ao estilo antigo, rígidas e inegociáveis, simplesmente não funcionam" (2004, p. 33). Bauman revê conceitos, em sua opinião, tidos como estanques até então, como o fato do pertencimento a uma nação. E comenta que fatores como "identidade nacional" e mesmo a ideia geral de "nação" são convencionados tal qual uma ficção e não são parte natural da vida humana. As construções abstratas, num modo geral, estão passando por um processo de liquefação:

Estamos agora passando da fase sólida da modernidade para a fase fluida. E os fluidos são assim chamados porque não conseguem manter a mesma forma por muito tempo e, a menos que sejam derramados num recipiente apertado, continuam mudando de forma sob a influência até mesmo das menores forças" (2004, p. 57).

Logo, para Bauman, assim como para Hall, o ser humano de hoje se insere em qualidades híbridas, fluídas e fragmentadas.
Assim, o que podemos pensar é em um novo ser humano, aquele cujas raízes não mais estão tão atarracadas ao lugar onde nasceu. O poeta alagoano Ângelo Monteiro escreveu um livro intitulado Todas as coisas têm língua (2008), cujo poema "Os sem raízes" alude à possibilidade dos indivíduos enfaticamente fragmentados, sem origens certas. Vejamos o texto:

Os que não têm raízes Ancoram em qualquer porto. Para eles as paisagens são iguais. $O$ céu é o mesmo céu. O mar é o mesmo mar. Apenas algumas nuvens mudam de lugar.

Os que não têm raízes Acostumam-se com o tempo. Só não sabem pedir um cobertor à tempestade Nem chorar na amurada dos navios A saudade do porto que deixaram.

Os invernos podem lhes provocar resmungos

Mas o verão, por mais que seja lúcido, Está aí para isso mesmo.

Que o sol se esbanje sobre suas cabeças Ou não se esbanje, O seu relógio continua a andar Com ou sem ponteiros.

Afinal que lhes resta por esperar?

No ápice da ideia do desenraizamento e da fragmentação das identidades fixas, os indivíduos não somente desempenhariam vários "eus" dentro da vida social, não apenas não pertenceriam a lugar nenhum, 
como também se transformariam em seres quase assígnicos. Ou seja, a mecânica das significações de referência de alguém pós-moderno, cuja identidade, ao estilo antigo, rígida e inegociável, simplesmente não funciona. Funcionaria, de fato, duma maneira cujo objetivo seria extinguir as próprias significações referenciais desde que, para eles, os personagens do poema de Monteiro, um lugar seria como qualquer lugar (um porto qualquer para ancorar), e o processo de referência, então, entraria em pane. É claro que, aqui, falar é crer. Mencionar coisas como "assígnico" ou "processo referencial" já é crer que nossa realidade é permeada por signos. Seriam eles incontáveis, nossos elementos primordiais, como a água é para os peixes ${ }^{1}$.

Em nosso entendimento, os seres humanos estão sempre em um processo infinito de significação, ou seja, a realidade em geral está eternamente nos enviando uma mensagem. O todo, decerto imensurável, de tais significações nos vai estreitando o ser dentro dum jeito específico, dentro de determinadas maneiras, dentro de alguma cultura. Vamos aprendendo vários códigos de significações como se tudo fosse uma organização, por mais complexa e confusa que seja, de elementos que se relacionam de alguma forma. Segundo a "semiótica da cultura"2, não só todo viés das artes, mas

\footnotetext{
${ }^{1}$ Baseado em Merleau-Ponty: "a linguagem é o nosso elemento, como a água é o elemento dos peixes” (1960, p. 25). Nosso entendimento aqui sobre isso é ter a linguagem como tudo que se faz significar, não unicamente a linguagem verbal.

${ }^{2}$ Aquela de origem russa, tendo Yuri Lotman como sua figura de maior proeminência.
}

como cada linguagem própria limita e dita suas predeterminações, ou seja, segundo Lotman, "cada linguagem, é não só um sistema de comunicação, mas ainda um sistema modelizante, ou melhor dizendo, essas duas funções estão indissoluvelmente ligadas" (1978, p. 44-45). Logo, a impressão imediata da realidade, também chamada de "poesia" por alguns, se e nos organiza por meio de ordens sensoriais, modelos de comportamento e linguagem, apresentando-se como verdadeiros impérios de paradigmas. Mesmo para a semiótica em geral, parece-nos, os processos de apreensão da realidade se dão pelos signos:

Como sistema-padrão organizado culturalmente, cada linguagem nos faz perceber o real de forma diferenciada organizando nosso pensamento e constituindo nossa consciência. A mediação do mundo pelo signo não se faz sem profundas modificações na consciência, visto que cada sistemapadrão de linguagem nos impõe suas normas, cânones, ora enrijecendo, ora liberando a consciência, ora colocando sua sintaxe como moldura que se interpõe entre nós e o real (PLAZA, 1987, p. 19).

É necessário salientar que linguagem no sentido semiótico pode ser qualquer tipo de código comunicativo, sendo a esfera verbal, talvez, àquela que mais nos atentamos ou somos educados para compreender. Porém, um gesto com a cabeça, por exemplo, pode passar a mensagem que se quer assim como uma frase dita ou escrita referente a tal ato; a imagem-ação do mundo é também sígnica nesse sentido, haja vista que aqui 
nosso entendimento de signo é triádico, ou seja, de origem peirceana ${ }^{3}$.

Logo, então, a apreensão de tudo aquilo que nos rodeia e inclusive de nós mesmos se daria por significações. Octavio Paz diria que "o homem é um ser que se criou ao criar uma linguagem. Pela palavra, o homem é uma metáfora de si mesmo" (1982, p. 41). Nós pensamos por meio dos signos e somos pensados por eles, pois, depois de criados, referenciados, entendidos, descobertos, eles, os signos, atingem certo status normativo, ou seja, acabam por nos indicar e instruir perante o mundo em geral.

$E$ É fato que nascemos dentro de um mundo de significações e vamos tanto experimentando quanto somos iniciados dentro deste mundo. Umberto Eco dá o exemplo de um garoto de quatro anos que "de barriga para baixo, estendido sobre a mesa, e, fazendo de eixo sua própria bacia, começa a rodar com os braços e as pernas estirados como o ponteiro de uma bússola dizendo: 'Sou um helicóptero'” (1976, p. 105). Este garoto percebeu e internalizou a ideia do que era um helicóptero (o Interpretante na tríade peirceana) e pode representá-lo de diferentes maneiras (fará de outra forma se tentar desenhar um helicóptero, salienta Eco), assim como pode reconhecer e saber diferenciar as coisas todas do mundo, ou seja, cada signo único e individual. Octavio Paz enfatiza: "O mundo não é um conjunto de coisas, mas de signos: o que

\footnotetext{
${ }^{3}$ Peirce (1972, p. 94) define o signo como algo que, sob certo aspecto ou de algum modo, representa alguma coisa para alguém. Dirige-se a alguém, isto é cria na mente dessa pessoa um signo equivalente ou talvez um signo melhor desenvolvido.
}

denominamos coisas são palavras, uma montanha é uma palavra, um rio é outra; uma paisagem é uma frase." E se indaga: "O que é o poeta senão um tradutor, um decifrador?" (1984, p. 98).

Assim, se estamos num momento de hibridação do ser e se somos mediados por significações, princípios reguladores imanentes de certa univocidade do ser se conservam em sua relação com o mundo que o rodeia. Não fosse assim e estaríamos não em uma crise de identidade, em que se aventura em pensamento pelos vales os quais não se é, sempre tendo o lar para voltar, mas, de fato, sem identidade alguma, já não mais nos reconheceríamos em relação ao outro e, por conseguinte, nem a nós mesmos, pois não teríamos para onde voltar, desde que seríamos tão fluidos que não conseguiríamos manter a mesma forma por muito tempo, ideia ilustrada no poema de Monteiro como a passagem das horas de um relógio que jamais para mesmo que não conte com ponteiros. No entanto, para "funcionarmos", assim como para todos os códigos semióticos funcionarem, é preciso que recorramos às próprias raízes, sejam elas quanto mais híbridas ou fracas. O fator principal é que as raízes existam. Não existissem e teríamos um mundo feito apenas de relativismos, já baseado no sonho de uma linguagem sistematizada em diferenças. Fôssemos todos diferenças, Eagleton bem notou, "ninguém seria capaz de dizer qualquer coisa inteligível - e não poderiam existir poesia, sinais de trânsito, cartas de amor ou folhas de registro, bem como nenhuma afirmação de que tudo é peculiarmente diferente de tudo o mais". (p. 30, 2003). 
Atentando à menção à poesia feita por Eagleton: no mundo das diferenças, realmente, ela mesma não poderia sobreviver. Aqueles para quem não faz diferença se "os invernos podem lhes provocar resmungos", pois "o verão, por mais que seja lúcido/Está aí para isso mesmo", lembram muito um outro caso na literatura: Alberto Caeiro, o heterônimo mestre do escritor português Fernando Pessoa. Em O Guardador de Rebanhos, Caeiro descreve a si mesmo em poemas: alguém que não enxerga significados extras ao que vê. Alguém que se atenta às coisas da natureza e nega qualquer sentimento que elas possam falar ou ter. "O que vemos das coisas são as coisas". ${ }^{4}$ Tudo é tal qual se apresenta. Caeiro assim contraria o pensamento de que tudo é representação de algo outro. Para ele, uma árvore é apenas uma árvore em si, e não qualquer sentimento, qualquer figuração poética, qualquer emoção que a árvore possa ter. Isso, é claro, antes de tudo, causa um impasse poético:

Como a obra de Caeiro canta um mundo governado pela ausência de signos, ela acaba criando um impasse poético, isto é, põe em xeque a própria sobrevivência, a própria pertinência da poesia, uma vez que, num universo desprovido de sistemas de significação, poemas já não seriam necessários. (GAMA, 1995, p. 31).

O metaimpasse, feito por Caeiro de assignificar a realidade por justamente

${ }^{4}$ PESSOA, Fernando. Poemas de Alberto Caeiro. Edições Ática, S.A.R.L. Lisboa: 1970, p. 48. significá-la com poesia, está também no poema de Ângelo Monteiro. Se os que não têm raízes "acostumam-se com o tempo", embora não saibam "pedir um cobertor à tempestade, nem chorar na amurada dos navios a saudade do porto que deixaram", muito precisamente é porque não houve processos de significação, de referência quando em outros portos, lugares, sensações, momentos. Logo, eles poderiam a todo o momento perderem a si mesmos, perderem as próprias identidades, não serem mais o que foram, como uma sociedade realmente líquida que mudasse tanto sua linguagem e seus hábitos que fosse impossível comunicarem-se com seu passado. Em uma das aventuras de Gulliver, do escritor Jonathan Swift, o protagonista narra sobre um peculiar país:

Como a língua deste país sofre contínuas modificações, os struldbrugs de uma época não compreendem os de outra nem lhes é possível, depois de duzentos anos, travarem conversação alguma (além de umas poucas palavras gerais) com os seus vizinhos, os mortais; e têm assim a desvantagem de viver como estrangeiros em sua própria terra. (1971, p. 198).

A situação de estrangeiro na própria terra, então, não apenas implica um estado alheio de não pertencimento regional, mas também permanecer fora do ritmo da semântica temporal. A passagem destacada, mesmo provinda de ficção, tem o poder de mostrar algo real: que a linguagem, o código comunicacional, muda durante o tempo assim como os conceitos para os 
quais aponta. Alguns dizem do lado bom do esquecimento, pois com ele já bastaria para velhos objetos se tornarem novos quanto a seus significados, e aí o poder de sentir prazer sempre com as mesmas coisas não cairia no horror de conhecer. "O leitor ideal" - diria Manguel - "tem uma aptidão ilimitada para o esquecimento" (2009, p. 34). Mas o horror do conhecimento é necessário para que não voltemos a ser a tábula rasa que segundo o pós-modernismo somos quando nascemos $^{5}$ e, assim, não termos em nós, leitores quaisquer, à leitura de nada, pois qualquer construção sintática/semiótica não teria efeito algum. A interpretação das coisas não aconteceria, pois não haveria a significação fugidia das coisas em si.

Dado que cada cultura tem em si suas próprias esferas e fronteiras sociocomunicacionais ${ }^{6}$, o modo que a significação se daria, e aí também o poético, sendo não a simples subversão de uma lógica qualquer previsível, mas determinada subversão. Para, por exemplo, a poesia conseguir ser o que é, ela deve subverter certa norma de determinado código ao qual está relacionada. $O$ código então é o processo referencial, a convenção, a cultura em geral:

\footnotetext{
${ }^{5}$ Judith Butler, autora americana, radicaliza a questão de nascermos qualquer coisa que seja; foca principalmente nas identidades de gênero, embora a ideia de não nascermos coisa alguma, e segundo ela, irmos nos tornando algo por uma "perfomance repetitiva", cabe como bandeira aos píncaros do pensamento pós-moderno.

${ }^{6}$ Canclini: "a clássica definição socioespacial de identidade, referida a um território particular, precisa ser complementada com uma definição sociocomunicacional." (1999, p.59).
}

[...] cultura é uma acumulação histórica de sistemas semióticos (linguagens). A tradução dos mesmos textos para outros sistemas semióticos, a assimilação dos distintos textos, o deslocamento dos limites entre os textos que pertencem à cultura e os que estão além dos seus limites constituem o mecanismo da apropriação cultural da realidade. A tradução de uma porção determinada da realidade para uma das linguagens da cultura, sua transformação em texto, ou seja, em informação codificada de certa maneira, a introdução de tal informação na memória coletiva: esta é a esfera da atividade cultural cotidiana. (LOTMAN apud OSIMO, 2006).

Dá-se a perceber que, para Lotman, a cultura é um texto no qual se organizam vários outros textos. Ele percebe que o trabalho primordial da cultura consiste em organizar estruturalmente o mundo que rodeia o homem. Ela seria, então, a própria criadora de certa sociosfera estrutural ao homem, algo que lhe possibilitaria a vida, não a orgânica, mas a de relações humanas, assim como a biosfera que, por sua vez, acarretaria a vida propriamente vital (LOTMAN, 1996, p. 78).

A cultura é um sistema que opera por meio de significações paulatinas, estereotipadoras, e por assim dizer, modelizantes. Logo, a memória fará parte importante da caracterização da cultura; segundo Lotman, ela, a cultura, "é assegurada, em primeiro lugar, pela presença de alguns textos constantes e, em segundo lugar, pela unidade dos códigos ou por sua invariância ou pelo 
caráter ininterrupto e regular de sua transformação" (LOTMAN, 1996, p. 157). Logo, os fatos constantes, modelizantes, repetitivos têm não outro lugar senão a própria memória para se fixarem. A respeito desta relação, o filósofo francês Bergson salienta que

se colocarmos a memória, isto é, uma sobrevivência das imagens passadas, estas imagens irão misturar-se constantemente à nossa percepção do presente e poderão inclusive substituí-la. Pois elas só se conservam para tornarem-se úteis: a todo instante completam a experiência presente enriquecendo-a com a experiência adquirida; e, como esta não cessa de crescer, acabará por recobrir e submergir a outra. É incontestável que o fundo de intuição real, e por assim dizer instantâneo, sobre o qual se desenvolve nossa percepção do mundo exterior é pouca coisa em comparação com tudo o que nossa memória nele acrescenta. (1999, p. 69).

Bergson toca num ponto crucial: a memória é vital para que os mecanismos sígnicos funcionem em nós. Só por ela temos a capacidade de nos entendermos dentre os vários códigos semióticos que a nós se apresentam durante a vida. Logo, o que temos disso tudo é a realidade que nos atravessa por signos. O texto de nossa cultura seria formado por vários outros textos, ou linguagens, que ordenam o mundo ao nosso redor e também a nós mesmos como parte da realidade do todo.

Então, se os signos nos organizam numa malha deles mesmos, e aí estamos envoltos na cultura como texto semiótico, fatos que ocorrem com a desorganização nos soariam estranhos: para alguns, certas cores não combinam entre si, para outros, certos assuntos não se relacionam com determinados momentos sociais, e isso significa que há um choque entre códigos semióticos tidos por nós como quase, senão de todo, estanques. Porém o aspecto poético não se configura de maneira unicamente de estranheza, não é uma simples negação aos signos e seus sistemas, mas uma subversão destes. Ressalta sobre o assunto, o poeta Mario Faustino:

Refiro-me à capacidade que tem o artista, em geral, e em especial o poeta, de perceber seu objeto, cada objeto, em sua quase absoluta individualidade e não como simples ideia representativa de uma coleção de objetos semelhantes. Lembras-te, decerto, do exemplo clássico em psicologia: geralmente quando um homem comum percebe uma laranja não está percebendo "uma” laranja individualmente e, sim, apenas, a representação de toda a classe de "laranja". O artista, o poeta, percebe e é especialmente capaz de expressar uma laranja, esta e não aquela. (1977, p. 41, o grifo é nosso).

Assim, a poesia se insurge na vida cotidiana, subvertendo a ordem dos fatores tida para nós como lógica. Portanto, não só a poesia verbal, a que mais se difunde, é, então, possível, mas podemos pensar que para todo código semiótico há a possibilidade de uma poesia própria. A ideia dum ser "sem signos", um possível e real cético à metafísica tem, entre outras, ironicamente, "suas raízes" no pensamento de Derrida: 
em Posições (1972), em sua conversa com Julia Kristeva, o franco-argelino coloca em questão a possibilidade do significado transcendental, pois que este deve "passar pela difícil desconstrução de toda a história da metafísica que impôs e não deixará de impor essa exigência fundamental (a de um significado transcendental)" (p. 26). O sonho de Derrida parte da sua própria implicância com os binarismos hierárquicos da civilização ocidental, desde masculino e feminino até significante e significado. Provavelmente, tivesse se aprofundado, ele ficaria mais feliz com o threesome sígnico da semiótica americana. Mas talvez porque a semiótica de Peirce tenha se mostrado mais humilde que a semiologia de Saussure, pois aquela se pretendia como um conjunto de princípios de lógica para seus objetos, e esta era tão narcisista que fez de si mesmo ciência e objeto, Derrida tenha seguido a premissa, algo que vem sendo feito em inúmeros lugares, por mais que as realidades drasticamente se diferenciem uma da outra, de que se a França espirra, o mundo todo fica resfriado.

Logo, então, o ápice da possibilidade dos sem raízes é senão uma inadequação de descrição dum falso zeitgeist que ocorreria no mundo todo interconectado de hoje em dia, pois sabemos que, para muitos povos à margem, ainda que haja a tentativa dos estudos culturais de voltar os ouvidos para eles, querendo ouvir a voz dos alheios e não compreendendo que os alheios querem mais é deixar de serem o que são, o que se tem como a celebrada condição pósmoderna nada mais é - diz Denis Epko
- "que um grito hipocrítico de autoelogio de crianças mimadas e superalimentadas" (1995, p.122). E apesar do claro esforço da contemporaneidade desta descrição de si mesma, como se vivessem pensadores como Bauman e Hall numa eterna nostalgia do presente, a possibilidade da metafísica, dos significados transcendentais e das hierarquias ainda bem sobrevivem. A desconstrução de um fato resultou em outras construções dele mesmo.

E então, o poético vai surgindo como objeto e ao mesmo tempo, de forma também pedagógica, no reconhecimento subjetivo. As não raízes, a fluidez, as identidades não fixas são também um esboço utópico dum espaçotempo em que as convenções estariam suspensas. Eagleton diria sobre que

está convencionado que assassinos de crianças sejam punidos, que homens e mulheres que trabalham possam deixar seus empregos, que ambulâncias em alta velocidade a caminho de um acidente de tráfego não sejam bloqueadas só porque quero que se lixem. Qualquer um que se sinta oprimido por tudo isso tem de estar padecendo de grave supersensibilidade. (2003, p.30).

Aí está a convenção cuja origem, seja metafísica, seja mero acordo, venha da crença em Deus ou na religião da ciência, é o que ordena, mesmo confusamente, a realidade da qual fazemos parte. Ângelo Monteiro, quando desenraizou seus personagens em seu poema, não apenas descreveu a impossibilidade da não referência, como também negou toda uma celeuma sobre a era das não 
significações que, num afã quase juvenil ${ }^{7}$, segue uma gama teórica mostrada aqui. Ao contrário do que se possa pensar, que a era do pós-moderno, por estar sem amarras e raízes, seria mais criativa, desenvolta e interessante na construção de coisas novas, ela, na verdade, acaba gastando muito de seu tempo a desconstruir velhos pilares de ideias, resultando numa época cheia de pastiches, reconfecções, remakes, releituras, reciclagens, sequências, e uma grandiosa orquestração do já visto, já lido, já visitado e já ouvido. Afinal, a nós todos, o que nos resta a esperar?

\section{REFERÊNCIAS}

BAUMAN, Z. Modernidade líquida. Trad. Plínio Dentzien. Rio de Janeiro: Jorge Zahar Editor, 2001.

. O mal-estar-moderno e pós-moderno.

In: 0 mal-estar da pós-modernidade. Tradução de Mauro Gama, Cláudia Martinelli; revisão técnica de Luís Carlos Fridman. Rio de Janeiro: Jorge Zahar, 1998, p.7-12.

CULLER, J. O que é teoria? In: Teoria literária: uma introdução. Tradução de Sandra Vasconcelos. São Paulo: Beca, 1999, p.11-25.

DERRIDA, J. Implicações (entrevista a Henri Rose). Semiologia e gramatologia (entrevista a Julia Kristeva). In: Posições. Tradução de Tomaz Tadeu da Silva. Belo Horizonte: Autêntica, 2001, p.9-44.

EAGLETON, T. A política da amnésia. A

\footnotetext{
${ }^{7}$ É uma alusão a Tolstói que paradoxa em O Diabo: "em norma, os conservadores são tidos como pessoas mais velhas, e aqueles em favor das mudanças são os mais jovens. Não está isso bem correto. Geralmente os conservadores são pessoas jovens: aqueles que querem viver, mas que não pensam em como fazê-lo, e assim não tendo tempo a pensar, acabam, portanto, a aceitar como um modelo de vida algo que já tenham visto. (2000, p.3, tradução nossa).
}

ascensão e queda da teoria. In: Depois da teoria: um olhar sobre os Estudos Culturais e o pós-modernismo. Tradução de Maria Lucia Oliveira. Rio de Janeiro: Civilização Brasileira, 2005, p.13-65.

ECO, U. A Estrutura Ausente: Introdução à pesquisa semiológica. 7.ed. São Paulo, Perspectiva, 2000.

HALL, S. A identidade cultural na pósmodernidade. 8.ed. Rio de Janeiro: DP\&A, 2003.

MONTEIRO, A. Todas as coisas têm língua. Recife. 2008.

OSIMO, B. Logos group: curso de tradução moderna. Disponível em: <http://www. logos.it/pls/dictio-nary/linguistic_resources. cap_1_28?lang=bp>. Acesso em: 01 jun. 2011.

PAZ, O. $\mathrm{O}$ arco e a lira. Rio de Janeiro: Nova Fronteira, 1982.

PEIRCE, C. S. Semiótica e Filosofia. Trad. de Octanny Silveira da Mota e Leônidas Hegenberg. São Paulo: Cultrix, 1972.

PESSOA, F. Poemas de Alberto Caeiro. Lisboa: Edições Ática, S.A.R.L., 1970.

PLAZA, J. Tradução intersemiótica. São Paulo: Editora Perspectiva, 2003.

\section{LEITURAS COMPLEMENTARES}

CANCLINI, N. G. Consumidores e cidadãos: conflitos multiculturais da globalização. Rio de Janeiro. Editora UFRJ, 1999.

CULLER, J. A desconstrução. In: PETERS, M. Sobre a desconstrução: teoria e crítica do pós-estruturalismo. Tradução de Patrícia Burrowes. Rio de Janeiro: Record Rosa dos tempos, 1997, p.99-127.

EPKO, D. in SHOHAT, E.; STAM, R. Crítica da imagem eurocêntrica. São Paulo: Cosac 
Adrian Lincoln Clarindo

Naify, 2006.

FAUSTINO, M. Poesia: experiência. São

Paulo: Ed. Perspectiva S.A., 1977.

GAMA, R. Guardador de signos; Caeiro em pessoa. São Paulo: Perspectiva, 1995.

LOTMAN, I. La semiosfera: semiótica de la cultura e del texto. Trad. Desiderio Navarro. Madrid: Ediciones Cátedra, 1996.

MANGUEL, A. À mesa com o chapeleiro maluco: ensaios sobre corvos e escrivaninhas. São Paulo: Companhia das Letras, 2009.

TOLSTOI, L. The devil. Louisiana: Dotlit Press, 2000 .

Recebido para publicação em 27 de maio de 2013 Aceito para publicação em 25 de out. de 2013 